the step-by-step articulation of public health and education policies in the school space, an action already foreseen in the federal government's "Prevention Is Also Teached" programs, and "Health in School - PSE" In the joint state resolution of SES/SEE that provides for STD/AIDS prevention actions and definition of the transfer of condoms to schools. Experience shows us that it is possible to distribute condoms in schools on an ongoing basis, and it is fundamental to articulate the school/basic health unit.

\section{P4.09 BRAZILIAN MULTICENTRIC CAMPAIGN ON HIVIAIDS}

Andrey Oliveira da Cruz, Bruna Kariny de Oliveira Pereira. International Federation of Medical Students' Associations of Brazil, São Paulo - SP, Brazil

\subsection{6/sextrans-2017-053264.506}

Introduction HIV and AIDS represent one of the greatest concerns in global health in the last three decades. In Brazil, the percentage of people living with HIV and dying with AIDS increases every year. The number of cases in the south of Brazil is bigger than in the rest of the country, particularly in Rio Grande do Sul and Santa Catarina as the second and third states with the largest numbers. Medical students from the International Federation of Medical Students Association of Brazil (IFMSA Brazil) in the south of the country conducted this study to better comprehension of Brazilian citizens' understanding about the subject.

Methods This study investigated the profile of general population in three Brazilian cities (Curitiba, Londrina and Tubarão), identifying the sociodemographic aspects and knowledge level related to HIV and AIDS, in a descriptive and quantitative analysis. Data was collected through a questionnaire with nine questions, in November 2016.

Results 343 individuals, $57 \%$ female and the majority of them between 21 and 30 years old. The answers showed an alarming situation in the south region of Brazil. Almost half of them $(49.6 \%)$ did not know about their serology for HIV, meanwhile $60.6 \%$ revealed already being worried about that. Regarding HIV and AIDS definition, 71.7\% did not know the difference between the virus and the syndrome. When asked about a method of prevention for HIV and other STIs, more than $90 \%$ knew how to prevent themselves and most of them mentioned condoms as the method used. Only $41.4 \%$ reported using condoms regularly. When asked about social interaction with people living with HIV, 74.6\% would not have sexual relations and $16.9 \%$ would not be friends with someone living with the virus.

Conclusion One of the reasons for the massive numbers of HIV cases in the south of Brazil is the lack of knowledge of the population. Knowing the social determinants and population profile allows integrative practices, as the development of new action strategies to improve health promotion and health education regarding HIV and AIDS.

\section{P4.10 IFMSA BRAZIL'S EXPERIENCE ON HEALTH PROMOTION AND EDUCATION IN HIVIAIDS}

Andrey Oliveira da Cruz, Rafael Silveira Batista, Bruna Kariny de Oliveira Pereira. International Federation of Medical Students' Associations of Brazil (IFMSA Brazil), São Paulo - SP, Brazil

10.1136/sextrans-2017-053264.507
Introduction The International Federation of Medical Students' Associations of Brazil (IFMSA Brazil) is a nonprofit, nonpartisan and non-governmental organisation representative of Brazilian medical students. IFMSA Brazil was founded in 1991 and it is currently present in 95 medical schools around the country, at 26 Brazilian states. IFMSA Brazil envisions promoting a positive impact in society by allowing medical students to become leaders in health advocate, to find and to develop their potential. IFMSA Brazil acts through priority areas, defined by Standing Committees, developing projects and programs that may impact on society aiming health promotion and education. The Standing Committee on Sexual and Reproductive Health including HIV/AIDS (SCORA) brings the subject to discussion and engages Brazilian medical students to advocate on this specific field.

Methods We analysed IFMSA Brazil's Online System of Activities and Reports (SOLAR), which archives all projects and activities held by the Federation in its 95 Local Committees. We considered all the post-projects submitted to the platform of SCORA in 2016.

Results We received 108 activities submissions related to HIV, HPV and syphilis. The main activities developed were Candlelight Memorial Day, Health Care Blitzes, "Adolescer" - a Comprehensive Sexual Education Project for Teenagers, Campaigns of Act Against AIDS, Sexual Education Projects directed to elderly and sex workers and general events related to sexual and reproductive health in medical education.

Conclusion Developing new strategies of health promotion and education in sexual and reproductive theme may help different communities and improve education of Brazilian medical students. IFMSA Brazil is acting in a volunteering work to raise medical students' voice and engage advocacy in health, allowing the health care attention to neglected populations and preventing the increase of sexually transmitted infections and other diseases.

\section{P4.11 "I THINK IT HAS BEEN A NEGATIVE INFLUENCE IN MANY WAYS BUT AT THE SAME TIME I CAN'T STOP USING IT": SELF-IDENTIFIED PROBLEMATIC PORNOGRAPHY USE AMONG A SAMPLE OF YOUNG AUSTRALIANS}

${ }^{1}$ Angela Davis, ${ }^{1}$ Elise Carrotte, ${ }^{1}$ Margaret Hellard, ${ }^{2}$ Meredith Temple-Smith, ${ }^{1}$ Megan Lim. ${ }^{1}$ Burnet Institute, Melbourne, Australia; ${ }^{2}$ University of Melbourne, Melbourne, Australia

\subsection{6/sextrans-2017-053264.508}

Introduction Online pornography use among young people has raised concerns over the potential for "pornography addiction". There are no diagnostic criteria for pornography addiction and little is known about young people's experience of this phenomenon. We asked a sample of young Australian's about the influence of pornography on their lives and analysed responses for themes of self-identified problematic consumption.

Methods Participants $(\mathrm{n}=1029)$ aged 15-29 years were recruited via Facebook to an online survey. Those who had ever viewed pornography $(n=856)$ were asked in an openended question: 'How has pornography influenced your life?'. Data were thematically analysed for sentiment and theme. Sub-themes were developed for responses, which indicated problematic usage including obsessive thoughts, compulsive 